\title{
ALQUIMIA: ISAAC NEWTON REVISITADO
}

\author{
Reginaldo Carmello Corrêa de MORAES ${ }^{1}$
}

- RESUMO: Nota sobre publicações recentes que revelam aspectos pouco conhecidos da biblioteca de Newton - os numerosos textos religiosos, místicos e herméticos. Os biógrafos de Newton resistiram muito até admitir que os escritos esotéricos fossem genuíno interesse do sábio e que tivessem importância para entender sua trajetória intelectual. As publicações aqui indicadas afirmam o contrário, seguindo trilha aberta por ensaio pioneiro de J. M. Keynes (1946).

- PALAVRAS-CHAVE: Isaac Newton; alquimia; história da ciência; esoterismo; física.

Três séculos depois da publicação de sua mais famosa obra, Princípios matemáticos da filosofia natural (1687), a imagem clássica, racional e bem comportada do pai da ciência moderna é desafiada por uma sombra, a do "último dos mágicos, o último dos sumérios e babilônicos". A ousada afirmação coube ao economista John Maynard Keynes (1971-1980), no ensaio biográfico Newton, the man, de 1946. Dez anos antes, Keynes comprara um lote de manuscritos de alquimia pertencentes a Sir Isaac, doando-os em seguida ao King's College. Ainda em nossos dias, contudo, Richard Westfall (1995, p.114), o famoso biógrafo de Newton, registra:

1 Instituto de Filosofia e Ciências Humanas - Unicamp - Campinas - SP - Brasil. 
Uma das grandes paixões da vida de Newton, como atesta um vasto corpo de documentos que se estendeu por mais de 30 anos, e uma investigação que inclui o contato com círculos alquímicos, como atestam suas cópias de tratados não publicados, permaneceram basicamente ocultas do conhecimento público, e assim permanecem até hoje. ${ }^{2}$

Os biógrafos de Newton resistiram muito para admitir que esses escritos esotéricos tivessem interesse para entender sua obra científica, o lado sério do sábio. No século XVIII, as Cartas filosóficas de Voltaire viam nisso apenas uma espécie de passatempo, destinado a descansar o espírito entre experimentos e deduções. Alguns historiadores do século XIX tentavam associar esses papéis a uma crise nervosa passageira, que teria abalado o pai da física moderna. Outros procuravam maquiar desajeitadamente as datas: as especulações místicas seriam o fruto de uma fase tardia e declinante do grande pensador. A esse respeito, um pequeno estudo de Charles Webster (1988, p.119) sentencia:

Introduziu-se um importante elemento de distorção nas descrições do surgimento da ciência moderna com a subestimação do grau em que autores como Paracelso, ou autores que pertençam à tradição do neoplatonismo ou do hermetismo, continuavam sendo parte integrante dos recursos intelectuais da élite educada até bem tarde no século XVII. É tão grande a evidência que indica o constante interesse em filosofias contrárias à filosofia mecanicista, que a única forma de acomodar essa grande anomalia foi separar os líderes da ciência considerando-os homens representativos de seu tempo - da maioria mais crédula e não representativa. Para a desgraça dos que propõem esta teoria, figuras de notável importância, incluindo o próprio Newton, acabam tendo vivo interesse pelo oculto. A única maneira de encontrar uma saída para esse fenômeno é adotar o recurso pouco convincente de postular uma divisão de personalidade nos cientistas acusados de serem inconsistentes na prática do ideal ilustrado.

Havia, enfim, quem considerasse tais elaborações simples metáforas e deslizes de um cérebro essencialmente racional. Contudo, freudianos ou não, fomos cada vez mais obrigados a perceber que lapsos e metáforas não são casuais, mas sintomas que revelam traços decisivos da vida e do pensamento. E Newton não parece escapar a essa regra.

Um desses relutantes biógrafos, Charles Lamb, garantia que Newton se recusava a acreditar em algo que não tivesse a clareza dos três lados de um triângulo. Mas o ensaio de Keynes e a leitura dos manuscri-

2 Trata-se de versão reduzida da obra maior de Westfall, Never at rest: a biography of Isaac Newton, Cambridge: Cambridge University Press, 1980. 
tos revelam coisa bem diferente sobre os impulsos, motivações e caminhos pelos quais o sábio perseguia suas hipóteses. Na base desse trabalho mental estava uma crença originária, obscura e bem pouco geométrica: Newton parecia acreditar firmemente que a verdade sobre o mundo havia sido impressa por Deus em alguns sinais - presentes em documentos sagrados, escritos em linguagem criptográfica, alegorias e símbolos. A experiência e a demonstração matemática, ao que tudo indica, eram um passo posterior de seu estudo. Numa célebre conversa com o astrônomo Halley, Newton dava a entender que se tratava de provar, pela dedução e pela experiência, algo que já sabia há muito tempo - e que, antes dele, já sabiam os antigos. As medidas do Templo de Salomão e o Livro de Daniel, por exemplo, trariam, codificados, segredos do mundo. É ainda Webster (1988, p.31) quem lembra:

Newton e seus companheiros não reconheciam nenhuma diferença radical entre seus estudos científicos e os estudos de textos sagrados. A analogia entre o livro da natureza e o livro da revelação era lugar-comum. Para o cientista, o comentário sobre textos alquímicos representava a aplicação de habilidades analíticas a uma via da verdade que tinha parentesco tanto com a revelação como com a natureza.

Não nos deveria espantar, portanto, que a biblioteca de Newton abrigasse, ao lado dos textos religiosos e da sabedoria dos antigos, uma enorme coleção de obras de escritores herméticos, os alquimistas, sobre a transmutação dos metais em ouro, a pedra filosofal, o elixir da vida.

Desse modo, a convicção inicial, intuída a partir dessas fontes pouco ortodoxas, era elemento decisivo para estimular e dirigir a atividade investigadora, selecionando hipóteses e indicando caminhos para o pensamento. Keynes lembra que a loucura de Newton era extremamente metódica, disciplinada. Os seus escritos de alquimia não eram passatempo mal cuidado e febril. Alguns eram registros precisos, sóbrios e pacientes de experimentos exóticos. Outros continham traduções e comentários minuciosos de autores herméticos, como um índice químico, em que classificava quase novecentos verbetes, comentando mais de cinco mil páginas de leituras rigorosas. Mais um detalhe importante é repetidamente ignorado pelos biógrafos ortodoxos: essas volumosas anotações haviam sido feitas exatamente durante os mesmos 25 anos dos principais estudos matemáticos de Sir Isaac, algo enfatizado por Westfall (1995, p.208) contemporaneamente:

(Newton) tampouco omitiu a alquimia, ao reunir seu legado filosófico. Ao contrário, uns bons $50 \%$ de seus extensos ensaios alquímicos, que tinham sido interrompidos pelos Principia durante dois ou três anos, vieram do período imediatamente posterior a estes. Se podemos julgar pela quantidade de 
manuscritos, Newton dedicou mais tempo à alquimia no início da década de 1690 do que a todas as outras coisas juntas.

É ainda Westfall (1995, p.112-3) que destaca outro fato revelador da vida intelectual do grande sábio:

Sólidas provas nos mostram ... que, como quer que tenha começado, a atividade alquímica de Newton incluiu sua introdução pessoal na sociedade basicamente clandestina dos alquimistas ingleses. Sua leitura da alquimia não se restringiu à palavra impressa. Há entre seus manuscritos um maço grosso de tratados sobre o assunto, em sua maioria não publicados, escritos por pelo menos quatro mãos diferentes. Como Newton copiou cinco dos tratados, além de algumas receitas, a coleção parece ter-lhe sido emprestada para fins de estudo e, por alguma razão, não foi devolvida.

Já se disse que a principal obra de Newton é um livro que muitos desejariam ter lido, mas poucos desejam ler. Os manuscritos de alquimia, por outro lado, são textos que muitos desejariam que não tivessem sido escritos. E isso não é jogo de palavras: os documentos doados por J. M. Keynes haviam sido recusados anteriormente pela Universidade, com o sintomático argumento de que não possuíam interesse cientifico. Quais os motivos dessa insistente negação do lado sombrio da estrela?

Uma das razões talvez tenha a ver com circunstâncias históricas, sociais e políticas. Afinal, há trezentos anos Sir Isaac é a figura mais venerada da tradição britânica, uma espécie de herói nacional, cujo rosto marca as notas de uma libra. Além disso, as imagens iluministas e vitorianas de Newton, símbolo imaculado de racionalidade, progresso e virtude, tinham de ser defendidas dos ataques de Leibniz, seu terrível rival alemão.

Mas haveria uma razão a mais para considerar irrelevante ou irreal esse outro Newton. É o historiador John Henry (1988) quem afirma: "Newton possui essa personalidade dividida simplesmente porque nós vemos ciência e magia como abordagens incompatíveis para a compreensão do mundo. Mas deveríamos reconhecer que magia, e mesmo ciência, significam diferentes coisas para diferentes culturas".

Webster (1988, p.34) acrescentaria, a esta observação, uma outra, relativa especificamente à história intelectual do século XVII:

A magia como representação de um ritual que tende a controlar forças consideradas causantes da sucessão dos acontecimentos caiu lentamente em um estado latente entre a élite intelectual, mas parece que a infra-estrutura conceitual da magia foi mantida com convicção durante um período muito mais longo. ... Conseqüentemente, é importante não supor que o declínio da magia operativa popular significava o completo abandono de uma visão mágica do mundo. 
Certamente poderíamos admitir que, para elaborar a teoria da gravitação, Newton não precisaria tomar de empréstimo aos autores herméticos aqueles comprometedores esquemas. Pode ser. Mas para a história e auto-análise das ciências, e para a compreensão de seus impasses e soluções, esses aparentes detalhes são decisivos. Como lembram alguns desses estudiosos, não é importante apenas descobrir como o sábio poderia ou deveria ter agarrado suas teorias e demonstrações, mas, também e sobretudo, como efetivamente ele as agarrou. E todo aquele que estuda os fatos humanos sabe que compreender uma época ou um autor significa também explicar aquelas sombras que eles obsessivamente recusam admitir. $^{3}$

MORAES, R. C. C. de. Alchemy: Isaac Newton Revisited. Trans/Form/Ação (São Paulo), v.20, p.39-44, 1997.

- ABSTRACT: A note on recent books about an unexplored side of Newton's library: religious, mystical and hermetic texts. Newton's biographers had resisted so much to believe that esoteric writings were in Newton's field of interest. Even if they recognized that, they didn't believe those strange works were important elements to understand his intellectual trajectory. The studies we mention here are saying just the opposite thing, exploring the way opened by the pioneer essay of J. M. Keynes (1946).

3 Vale registrar alguns materiais relevantes para quem se interesse em conhecer em mais detalhe esse aspecto da vida intelectual de Newton. As referências básicas são dois estudos de Betty Jo Teeter Dobbs. O primeiro, mais introdutório (embora muito detalhado e denso), é The Foundations of Newton's Alchemy [Cambridge University Press]. O segundo — The Janus Faces of Genius: the role of alchemy in Newton's thought (Cambridge University Press) - é um ensaio acadêmico com quatrocentas páginas de sólida argumentação, referências detalhadas a documentos, bibliografia extensa (nada menos do que quarenta páginas), tradução para o inglês de escritos alquímicos de Newton (originais em latim). A Oxford University Press publicou em 1988 uma coletânea, Let Newton Be!, em que são particularmente instigantes os seguintes artigos: "Newton, matter and magic", de John Henry; "The secret life of an alchemist", de Jan Golinski; "The God of Isaac Newton", de John Brooke; "Newton and the wisdom of the anciens", de Piyo Rattansi. O volume é fartamente ilustrado, em geral com reproduções de gravuras e capas de livros da história da alquimia, muitas delas com legendas decisivas para a compreensão do argumento dos ensaios. 
- KEYWORDS: Isaac Newton; alchemy; history of science; esoterism; physics.

\section{Referências bibliográficas}

DOBBS, B. J. T. The Foundations of Newton's Alchemy. Cambridge: University Press, 1974.

The Janus Faces of Genius: The Role of Alchemy in Newton's Thought. Cambridge: Cambridge University Press, 1993.

FAUVEL, J., FLOOD, R., SHORTLAND, M., WILSON, R. (Org.) Let Newton Be!: A New Perspective on His Life and Works. Oxford: Oxford University Press, 1988.

HENRY, J. Newton. Matter, and Magic. In: FAUVEL, J. et al. (Org.) Let New Be!: A New Perspective on His Life and Works. Oxford: Oxford University Press, 1988. p.127-45

KEYNES, J. M. Essays on biography. MacMillan: St. Martin's Press (1971-1980). (Collected Writing of J. M.Keynes).

WESTFALL, R. A vida de Isaac Newton. Rio de Janeiro: Nova Fronteira, 1995.

WEBSTER, C. De Paracelso a Newton: la magia en la creación de la ciencia moderna. México: Fondo de Cultura Económica, 1988. 